\title{
Langmuir
}

This document is confidential and is proprietary to the American Chemical Society and its authors. Do not copy or disclose without written permission. If you have received this item in error, notify the sender and delete all copies.

\section{Partitioning of clay platelets in Pickering emulsion polymerization}

\begin{tabular}{|r|l|}
\hline Journal: & Langmuir \\
\hline Manuscript ID & la-2015-03576h.R1 \\
\hline Manuscript Type: & Article \\
\hline Date Submitted by the Author: & 12-Nov-2015 \\
\hline Complete List of Authors: & $\begin{array}{l}\text { Brunier, Barthélémy; Université Claude bernard Lyon 1, LAGEP } \\
\text { SHEIBAT - OTHMAN, Nida; Université Claude Bernard Lyon1, Laboratoire } \\
\text { d'Automatique et de Génie des Procédés } \\
\text { Chevalier, Yves; University Claude Bernard Lyon 1, LAGEP } \\
\text { Bourgeat-Lami, Elodie; Laboratoire de Chimie et Procédés de } \\
\text { Polymérisation, LCPP - CNRS - CPE }\end{array}$ \\
\hline
\end{tabular}

\section{SCHOLARONE"}

Manuscripts 


\title{
Partitioning of clay platelets in Pickering emulsion
}

\section{polymerization}

\author{
Barthélémy Brunier ${ }^{1}$, Nida Sheibat-Othman ${ }^{1, *}$, Yves Chevalier ${ }^{1}$, Elodie Bourgeat-Lami ${ }^{2}$ \\ ${ }^{1}$ Université de Lyon, Univ. Lyon 1, CNRS, UMR 5007, Laboratoire d'Automatique et de Génie \\ des Procédés (LAGEP), 43 Bd du 11 Nov. 1918, 69622 Villeurbanne, France. \\ ${ }^{2}$ Université de Lyon, Univ Lyon 1, CPE Lyon, CNRS, UMR 5265, Laboratoire de Chimie, \\ Catalyse, Polymères et Procédés (C2P2), LCPP group, 43 Bd du 11 Nov. 1918, 69616 \\ Villeurbanne, France.
}

KEYWORDS. Laponite ${ }^{\circledR}$ clay platelets; multilayer adsorption; Pickering surfactant-free emulsion polymerization; QCM-D; TEM; energy-dispersive X-ray spectroscopy; conductivity; inductively coupled plasma-atomic emission spectroscopy.

\begin{abstract}
Partitioning of Laponite ${ }^{\circledR}$ disc-like clay platelets between polymer particles and bulk aqueous phase was investigated in Pickering surfactant-free emulsion polymerization of styrene. Adsorption of clay platelets plays an important role of stabilization in this system, influencing the particles' size and number, and hence the reaction rate. Adsorption isotherms show that, while clay platelets are almost fully exfoliated in water, they form multilayers on the surface of polymer particles by the end of polymerization, as confirmed by transmission electron microscopy (TEM). This observation is supported by quartz crystal microbalance, conductivity
\end{abstract}


and TEM measurements which reveal interactions between the clay and polystyrene, as a function of the ionic strength. The strong adsorption of clay platelets leaves a low residual concentration in the aqueous phase that cannot cause further nucleation of polymer particles, as demonstrated during seeded emulsion polymerization experiments in the presence of high excess of clay. A BET-type model for Laponite ${ }^{\circledR}$ adsorption on polystyrene particles matches the adsorption isotherms.

\section{Introduction}

Nanotechnology has grown to become an important area of research with tremendous scientific and economic potential, including microprocessor and biotechnology industries, allowing the synthesis of nanomaterials with great control regarding their structures, functions and compositions; e.g. organic/inorganic, polymeric, or biological, providing these materials with electro-mechanical and thermo-mechanical properties. ${ }^{1}$ Among the various technologies, manufacturing composite polymer materials including inorganic compounds allows improving end-use properties, such as stiffness and toughness, barrier properties, resistance to fire and ignition or optical properties, while reducing their cost. To this end, different kinds of inorganic materials have been used with different structures, including silica, iron oxide, titanium dioxide, metallic particles, and clays ${ }^{2,3}$.

Anisotropic particles such as clay platelets, carbon nanotubes, gold nanorods or semi-conductor nanowires have raised special interest over the last two decades due to their high aspect ratio resulting in enhanced overall performances ${ }^{4}$. Layered silicates commonly involved in nanocomposite synthesis belong to the structural family of the 2:1 phyllosilicates (usually from the smectite group) and have a sheet-like structure that consists of silica tetrahedral bonded to 
alumina or magnesia tetrahedral in a number of ways. Among them, Montmorillonite (MMT) and Laponite ${ }^{\circledR}$ (synthetic hectorite clay) are by far the most frequently used as inert modifiers and film-forming agents with attractive rheological properties ${ }^{5,6}$. Their lamellar structure consists of two dimensional platelets with a central layer made of $\mathrm{M}_{2-3}(\mathrm{O})_{6}$ octahedra ( $\mathrm{M}$ being either a divalent or a trivalent metal), sandwiched between two external layers of $\operatorname{Si}(\mathrm{O}, \mathrm{OH})_{4}$ tetrahedra. Laponite $^{\circledR}$ and MMT are similar in structure and thickness $(1 \mathrm{~nm})$, but the diameter of Laponite ${ }^{\circledR}$ $(30 \mathrm{~nm})$ is smaller than that of MMT $(0.1-1 \mu \mathrm{m})$. Therefore Laponite ${ }^{\circledR}$ clay can be easily exfoliated and dispersed in water as a colloidal suspension, making it particularly interesting for the stabilization of emulsions ${ }^{7}$ or latex particles ${ }^{8}$. Laponite $^{\circledR}$ and MTT also differ in the nature of the interlayer metal which is $\mathrm{Mg}$ for Laponite ${ }^{\circledR}$ and $\mathrm{Al}$ for MMT.

Polymer/clay nanocomposites can be manufactured by various processes including heterocoagulation $^{9}$ of the clay and the polymer particles, melt intercalation ${ }^{10,11}$, polymer intercalation from solution, exfoliation / adsorption, and covalent modification followed by in situ polymerization (bulk, solution and dispersion) ${ }^{12}$. Quite recently, waterborne polymer / clay nanocomposites elaborated by in situ free radical emulsion ${ }^{8}$ or miniemulsion ${ }^{7}$ have emerged. The main difference between emulsion and miniemulsion polymerization stands in the nucleation mechanism. In miniemulsion polymerization particles are formed through droplet nucleation, as free radicals generated in the aqueous phase are absorbed into monomer droplets of small size. In emulsion polymerization, particle nucleation takes place in the water phase while nucleation inside the droplets is negligible due to their small surface area. These processes are cheap and environmentally attractive because they do not involve organic solvent and the final products are easy to manipulate due to their low viscosity. In such systems, the production of composite materials implies the reaction of organic monomers in the presence of inorganic 
colloidal particles ${ }^{13}$. Emulsion polymerization has been first carried out by keeping the surfactant and adding chemically-modified Laponite $^{\circledR}$ as a supplementary additive ${ }^{14-20}$. Such functionalized Laponite ${ }^{\circledR}$ was coated with either cationic initiators or monomers through ion exchange, or by the reaction of the edge-hydroxyls with suitable organosilane molecules. Stable colloidal aqueous suspensions of composite particles with diameters in the range $50-150 \mathrm{~nm}$ were obtained consisting of a polymer core surrounded by an outer shell of clay platelets. It has been subsequently shown that bare (non-modified) Laponite ${ }^{\circledR}$ platelets could be used in emulsion polymerization without addition of surfactant ${ }^{21}$. In such surfactant-free heterophase polymerizations known as "Pickering emulsion polymerization", the adsorbed clay platelets stabilize the dispersion of polymer particles. It is therefore important to investigate the interactions between the clay and the polymer particles and evaluate the partitioning of the platelets between the different phases during the polymerization reaction. It is worth stressing that emulsion polymerization is considered in the present work and not mini-emulsion polymerization, which means that polymerization inside monomer droplets is precluded. Also, both $a b$ initio and seeded processes are considered. In the later, polymer particles are introduced before initiating polymerization; polymerization takes place inside these seed particles swollen with monomer. In $a b$ initio polymerization, no seed particles are introduced and nucleation of new particles takes place in the aqueous phase.

The adsorption of dislike Laponite ${ }^{\circledR}$ clay platelets and Ludox ${ }^{\circledR}$ silica particles on solid surfaces was firstly studied by Xu et al. ${ }^{22}$ using a Quartz Crystal Microbalance (QCM). It was concluded that Laponite ${ }^{\circledR}$ adsorption depended primarily on the surface charge of the polymer surface rather than the hydrophobic character of its surface. Interestingly, comparison between Ludox ${ }^{\circledR}$ silica and Laponite ${ }^{\circledR}$ suggested a simple monolayer formation for Ludox ${ }^{\circledR}$ silica, but a monolayer-to- 
multilayer transition for Laponite ${ }^{\circledR}$ as the concentration increased. Other adsorption studies of clay (and layered silicates) mainly concerned adsorption on modified surfaces in the objective of optimizing layer-by-layer assembly processes ${ }^{23}$. Clay platelets were reported to undergo fast adsorption; MMT adsorbs as a monolayer together with few overlapping platelets ${ }^{24,25}$ and kaolinite clay adsorbs as multilayers ${ }^{26}$.

The present study aims at investigating and modelling the partitioning of Laponite ${ }^{\circledR}$ clay stabilizing polymer particles during emulsion polymerization. The concentration of clay platelets was below the gelation concentration in order to focus on fluid colloidal suspensions of nonaggregated clay platelets. Assessment of the adsorption of Laponite ${ }^{\circledR}$ on polystyrene particles and characterization of Laponite ${ }^{\circledR}$ surface-aggregation were done by QCM-D, transmission electron microscopy (TEM), conductivity and elemental analysis (Inductively Coupled PlasmaAtomic Emission Spectroscopy, ICP-AES).

\section{Materials and Methods}

Materials. The monomer, styrene (Acros Organics, 99\% extra pure, stabilized) was stored in a fridge until used. Potassium persulfate (Sigma-Aldrich, minimum 99\%) was used as initiator. Laponite $^{\circledR}$ RDS (a synthetic clay from Rockwood additives) was used as stabilizer. Deionized water of $18 \mathrm{M} \Omega \mathrm{cm}$ resistivity was used throughout the work.

Laponite $^{\circledR}$ RDS. Laponite ${ }^{\circledR}$ is a synthetic layered silicate with a structure and composition closely resembling the natural clay hectorite ${ }^{27}$. The used grade contains the peptizing agent tetrasodium pyrophosphate $\left(\mathrm{Na}_{4} \mathrm{P}_{2} \mathrm{O}_{7}\right)$ at a concentration of $10 \mathrm{wt} \%\left(5.6 \% \mathrm{Na}_{2} \mathrm{O}\right.$ and $\left.4.4 \% \mathrm{P}_{2} \mathrm{O}_{5}\right)$ based on dry Laponite ${ }^{\circledR}$. Laponite ${ }^{\circledR}$ is made of disc-shaped crystals of $25 \mathrm{~nm}$ diameter and $0.92 \mathrm{~nm}$ thickness. Its density is $2570 \mathrm{~kg} \mathrm{~m}^{-328}$ and its melting point is $900{ }^{\circ} \mathrm{C}$. The platelet's 
specific surface area is $358.5 \mathrm{~m}^{2} \mathrm{~g}^{-1} 29$. Each crystal is composed of about 1500 unit cells/sheet, and each cell is composed of six octahedrally coordinated divalent magnesium atoms sandwiched between two layers of four tetrahedral silicon atoms. These groups are balanced by twenty oxygen atoms and four hydroxyl groups. Some magnesium atoms are substituted by monovalent lithium atoms and some positions are empty; such departure from stoichiometry provides a negative surface charge to the platelets that is balanced by sodium cations. The mean chemical composition is $65.82 \% \mathrm{SiO}_{2}, 30.15 \% \mathrm{MgO}, 3.20 \% \mathrm{Na}_{2} \mathrm{O}$ and $0.83 \% \mathrm{LiO}_{2}$, leading to the following chemical formula ${ }^{30}: \mathrm{Na}_{0.7}^{+}\left[\left(\mathrm{Si}_{8} \mathrm{Mg}_{5.5} \mathrm{Li}_{0.3}\right) \mathrm{O}_{20}(\mathrm{OH})_{4}\right]^{-0.7}$. Besides, Laponite ${ }^{\circledR}$ powder contains up to $8 \mathrm{wt} \%$ water, which should be either eliminated (by heating) or taken into consideration in the concentrations calculation. In the powder form, the crystals share interlayer $\mathrm{Na}^{+}$ions forming stacks.

Laponite $^{\circledR}$ dispersion in water. Laponite ${ }^{\circledR}$ nanoparticles are hydrophilic and the $\mathrm{pH}$ of their aqueous dispersions is 8-9. The zeta potential of Laponite ${ }^{\circledR} \mathrm{RD}$ at a concentration of $10 \mathrm{~g} \mathrm{~L}^{-1}$ in the presence of the pyrophosphate peptizing agent and $\mathrm{NaCl}\left(10^{-3} \mathrm{M}\right)$, is $-29.5 \mathrm{mV}$. Indeed, a strongly negative charge (700 elementary charges) is present on their basal faces due to the release of the $\mathrm{Na}^{+}$ions from the surface and a weakly positive charge appears on the rim of the disks due to protonation of the $\mathrm{OH}$ groups with hydrogen atoms of water (for $\mathrm{pH}<11$ ). ${ }^{28,31}$ This forms a colloidal dispersion of charged disc-like particles with a diameter of $\sim 25 \mathrm{~nm}$ and a thickness of $\sim 1 \mathrm{~nm}$ with negative charges on the crystal faces and small $\mathrm{pH}$-dependent positive charges on the edges, typically $10 \%$ of the negative charges. ${ }^{31}$ The interaction between platelets has been characterized by an isotropic van der Waals attraction and an anisotropic electrostatic interaction, which can be either repulsive (face-face, rim-rim) or attractive (rim-face) ${ }^{31} \mathrm{The} \mathrm{Na}^{+}$ 
counterions in solution screen the negative charges of the faces forming an electrical double layer.

Aqueous Laponite ${ }^{\circledR}$ suspensions undergo aging, which is characterized by $\mathrm{Mg}^{2+}$ ions leaching taking place according to the following chemical reaction in acidic medium. This reaction takes place in contact with $\mathrm{CO}_{2}$ and can so be avoided by working under inert nitrogen. ${ }^{28}$

$$
\mathrm{Si}_{8} \mathrm{Mg}_{5.45} \mathrm{Li}_{0.4} \mathrm{H}_{4} \mathrm{O}_{24} \mathrm{Na}_{0.7}+12 \mathrm{H}^{+}+8 \mathrm{H}_{2} \mathrm{O} \rightarrow 0.7 \mathrm{Na}^{+}+8 \mathrm{Si}(\mathrm{OH})_{4}+5.45 \mathrm{Mg}^{2+}+0.4 \mathrm{Li}^{+}
$$

The Laponite ${ }^{\circledR}$ RDS used in this work contains the peptizing agent : tetrasodium pyrophosphate (10 wt $\%$ based on clay) adsorbed onto the positively charged rims (edges); the tetravalent negatively charged pyrophosphate ions neutralize the rim charge and decrease electrostatic attractions between the positively charged rims and the negatively charged faces, and therefore avoid gelation. Reducing such interactions contributes to a longer stability of the dispersions in water. Note that low molar mass polyethylene oxide (PEO) molecules have also been reported to delay Laponite ${ }^{\circledR}$ aggregation by forming a steric barrier preventing contact between platelets. ${ }^{32}$

Reactor set-up and operation. A $1 \mathrm{~L}$ calorimeter reactor was used with mechanical stirring at 400 rpm using a three blades Bohlender propeller. The reaction was conducted at $70{ }^{\circ} \mathrm{C}$, and the reaction temperature was controlled using a thermostat bath. The reactor was equipped with five thermocouples inserted into the reactor, at the jacket inlet and outlet, in the heating bath and in the feed. A scale allowed measuring the flow rate of the introduced monomer in semi-continuous experiments. The reactions were carried out under oxygen free conditions, by degassing the reaction medium using nitrogen stream before the reaction. During the reaction, the stream of nitrogen was moved upwards off the reaction medium to the top of the reactor to maintain saturation of the gaseous atmosphere with nitrogen. These measurements were used to calculate 
the heat produced by the reaction and the calorimetric conversion. ${ }^{13}$ Samples were withdrawn at specific time intervals to measure the solids content (SC) (mass fraction of solid) using a thermogravimetric balance and the particle size, which allowed calculating the particle number density (assuming spherical particles). The solids content was used to calculate the amount of polymer and the monomer conversion, after subtraction of the mass of solids of clay and initiator. The ratio of the area of clay platelets' faces to the polymer particles area was calculated in order to get an estimate of the surface coverage of the latex particles by the clay and assess any excess of clay (see supporting information). ${ }^{33}$

Preparation of clay-armored polystyrene seed particles at $20 \mathrm{wt} \%$ solids content. This latex was prepared for seeded polymerizations. It was prepared batch-wise. $800 \mathrm{~g}$ of water containing $1 \mathrm{~g} \mathrm{~L}^{-1}$ clay was stirred for $30 \mathrm{~min}$ at ambient temperature, degassed using nitrogen and heated to $70{ }^{\circ} \mathrm{C}$ in the reactor. Then, $200 \mathrm{~g}$ of styrene was added and the polymerization was initiated by adding $1.6 \mathrm{~g}$ of potassium persulfate. The final mean particle size of the seed was $280 \mathrm{~nm}$ and the solids content was $20 \%$.

Seeded Polymerizations. 200 g of the above-described 20\% solids content seed were mixed in the reactor with $640 \mathrm{~g}$ of deionized water. $40 \mathrm{~g}$ of styrene was added to swell the seed particles for $1 \mathrm{~h}$ at ambient temperature under stirring at $200 \mathrm{rpm}$. Then, different amounts of clay were dispersed in the latex. Two series of experiments were performed: in the first one, the dispersion was allowed to equilibrate for one hour, and in the second one, for $12 \mathrm{~h}$. The dispersion was then heated up to $70{ }^{\circ} \mathrm{C}$, degassed, and the initiator was added to start the polymerization. After the disappearance of monomer droplets (as determined by calorimetric estimation of the conversion), which corresponded to about $50 \%$ conversion, $160 \mathrm{~g}$ of monomer was added semi-continuously at a flow rate of $0.02 \mathrm{~g} \mathrm{~s}^{-1}$ (therefore under monomer-starved conditions). At the end of monomer 
addition, a batch polymerization period of 30 min was applied to raise the conversion of the monomer above $90 \%$.

$A \boldsymbol{b}$ initio experiments. A batch period was first considered for particle nucleation followed by a semi-continuous part similar to seeded polymerizations. For the batch part, first $800 \mathrm{~g}$ of water containing different concentrations of clay was stirred for $30 \mathrm{~min}$ at ambient temperature and degassed using nitrogen and heating to $70{ }^{\circ} \mathrm{C}$ in the reactor. This was followed by the addition of $40 \mathrm{~g}$ of styrene, heating to $70{ }^{\circ} \mathrm{C}$ and the polymerization was initiated by adding $1.6 \mathrm{~g}$ of potassium persulfate.

Characterization of the particle size. Particle mean size and size distribution were measured by dynamic light scattering (Zetasizer, nano ZS, Malvern) at $25^{\circ} \mathrm{C}$ at a fixed scattering angle of $90^{\circ}$ after dilution in water. The $z$-average hydrodynamic diameter $\left(d_{p}, \mathrm{~nm}\right)$ is: $d_{p}=\sum n_{\mathrm{i}} d_{\mathrm{pi}}^{6} /$ $\sum n_{\mathrm{i}} d_{\mathrm{pi}}^{5}$, where $n_{\mathrm{i}}$ is the number density of particles of diameter $d_{\mathrm{pi}}$. Note that the size required in the calculation of the number of particles is that of unswollen polymer particles while the extracted sample contains swollen particles. Therefore, either enough dilution was applied in order to ensure full extraction of the monomer from particles into the aqueous phase or a correction was applied to calculate the size of unswollen particles (by deducing the volume of monomer in the polymer particles). The particle size was not corrected with regards to the adsorbed platelets thickness. Indeed, it was assumed that the platelets laid flat on the polymer particles (as will be demonstrated later using TEM) and therefore did not significantly contribute to the measured particle size, due to their small thickness $(1 \mathrm{~nm})$ compared to the particles diameter (of the order of $200 \mathrm{~nm}$ ). 
Transmission Electron Microscopy (TEM). A JEOL 2100F microscope, ("Centre

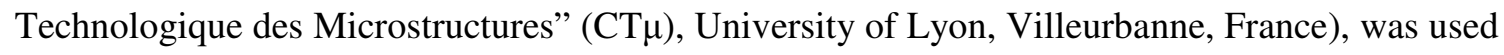
to observe the clay-armored latexes in high angle annular dark field mode. A small drop of diluted latex (5 wt $\%$ ) was deposited on a microscope grid (carbon-coated copper support), slowly dried in open air, and observed under $200 \mathrm{keV}$ acceleration voltage. Image analysis (using Digital Micrograph software) was used to evaluate the platelet and the interstitial water layer thicknesses. Using this TEM and the same procedure, Energy-Dispersive X-ray Spectroscopy (EDS) mapping of elements was carried out to determine the spatial distribution of carbon, oxygen, silicon and magnesium elements in the clay-armored particles. Similarly, Laponite ${ }^{\circledR}$ RDS dispersion in water was investigated by image analysis of TEM as well as cryo-TEM (see Supporting Information).

Surfactant-free polystyrene seed particles. This seed was done for conductivity and ICP-AES analyses. It was prepared batch-wise using $4 \mathrm{~g}$ potassium persulfate in $800 \mathrm{~mL}$ degassed water in a $1 \mathrm{~L}$ reactor. In order to produce different particles sizes $(200,400$ and $750 \mathrm{~nm})$, the reaction was carried out with different styrene concentrations $(2,4$ and $10 \mathrm{wt} \%)$. The final latexes were concentrated in a Rotavapor $^{\circledR}$ up to $20 \mathrm{wt} \%$ solids content. Such high concentration was required since both the conductivity and ICP-AES studies involved diluting the latex with a dispersion of clay. The latex was cleaned several times (about 10 times) with ion exchange resins (Dowex ${ }^{\circledR}$ Marathon $\left.{ }^{\mathrm{TM}} \mathrm{MR} 3\right)$ to eliminate free ionic species resulting from initiator decomposition and hydrosoluble species. The washing steps were repeated until a constant conductivity was obtained.

Conductivity measurements. The cleaned surfactant-free polystyrene latex described above was used $(S C=20 \%)$. A dispersion of clay in water was prepared and gently stirred for $24 \mathrm{~h}$, 
then added to the cleaned latex and allowed to equilibrate for $12 \mathrm{~h}$. Deionized water was added to reach the same solids content $(5 \mathrm{wt} \%)$ for all samples, with different clay concentrations. The conductivity was corrected for the effect of viscosity (measured with a MCR 302 Rheometer) by assuming a linear relationship between the conductivity and the viscosity. Indeed the mobility of ionic species is inversely proportional to the viscosity of the medium at constant temperature (Walden's rule). Thus, conductivities were rescaled in order to eliminate the effect of viscosity on conductivity as follows: $\sigma_{c o r r}=\sigma_{\exp } \frac{\eta_{r e f}}{\eta_{\exp }}$, with $\eta_{r e f}=1.003 \mathrm{mPa} . \mathrm{s}$ for all samples, and $\eta_{\exp }$ measured with a Anton Paar MCR 302 rheometer.

Inductively Coupled Plasma - Atomic Emission Spectroscopy (ICP-AES). Adsorption of clay platelets on polystyrene latex was investigated by measuring the residual magnesium $(\mathrm{Mg})$, silicon $(\mathrm{Si})$ and lithium $(\mathrm{Li})$ in water. A titration method was employed using at least two distinct wavelengths for each element: $279.8 \mathrm{~nm}, 280.3 \mathrm{~nm}$ and $285.2 \mathrm{~nm}$ for $\mathrm{Mg} ; 252.9 \mathrm{~nm}, 255.6 \mathrm{~nm}$ and $288.2 \mathrm{~nm}$ for $\mathrm{Si}$, and finally $610.4 \mathrm{~nm}$ and $670.8 \mathrm{~nm}$ for Li. The surfactant-free latex described above was used. Three series of experiments were realized: with cleaned, uncleaned latex, and cleaned latex followed by ionic strength adjustment by addition of $\mathrm{KCl}$. The clay dispersion was prepared as in the conductivity study, and the concentrations of the samples were all adjusted to $5 \mathrm{wt} \%$ solids content. Two methods of separation of polystyrene from free clay platelets in water were considered: (1) ultra-centrifugation of the samples at 40,000 rpm for 20 min (after validating that the platelets do not settle during centrifugation under such conditions), and (2) filtration through a syringe filter of $200 \mathrm{~nm}$ pore diameter (a test was also done to validate that particles do not pass through the filter but that the clay does). 
Quartz Crystal Microbalance (QCM-D). A QCM apparatus with dissipation monitoring technology (model D300, Q-Sense) was used to study the kinetics of clay adsorption. The measurements were performed in a cell coated with neutral polystyrene (QSX-305, Lot Oriel). All experiments were performed at $20{ }^{\circ} \mathrm{C} \pm 0.01{ }^{\circ} \mathrm{C}$, after achieving a stable baseline of resonance frequency (f) and energy dissipation (D). Four harmonics were detected $\left(1^{\text {st }}\right.$ fundamental harmonic, $3^{\text {rd }}, 5^{\text {th }}$ and $7^{\text {th }}$ overtones) for the frequency and dissipation (i.e. normalized energy lost per oscillation period which corresponds to the bandwidth divided by the resonance frequency). Two different concentrations of clay platelets were studied $\left(2 \mathrm{~g} \mathrm{~L}^{-1}\right.$ and $\left.10 \mathrm{~g} \mathrm{~L}^{-1}\right)$. First deionized water was injected into the measurement cell; after 2 min delay a stable baseline of frequency was achieved, three successive injections of fresh solution of clay platelets in water were made followed by a 2 min equilibration period before each measurement.

\section{Results and discussion}

\subsection{Investigation of the role of clay in emulsion polymerization}

Surfactant-free emulsion polymerization of styrene was carried out in the presence of clay by semi-continuous monomer addition, either in ab initio or in seeded modes, in order to infer the role of clay on the nucleation and stabilization of polymer particles.

\subsubsection{Effect of clay concentration in ab initio semi-continuous polymerization}

The objective of these experiments is to investigate the relationships between the clay concentration and the number density of nucleated particles and their stability. Figure 1 shows the results of a series of $a b$ initio semi-continuous experiments with different clay concentrations. At the beginning, the number of particles increased during a first period called 
nucleation period (Figure 1a). The end of the nucleation period, where the number of particles stopped increasing, was observed between 45 and $90 \mathrm{~min}$. The number of particles increased as a function of the clay concentration; the dependence on clay concentration was less at the high concentrations but no clear leveling off was observed. This led to an increase in the reaction rate and smaller particles at the same solids content (Figure 1b, c). As a second result, the clay particles were found to be quite efficient in ensuring particles' stability since the particles number remained constant until the end of the reaction, with $\mathrm{SC}=20 \%$, revealing neither coagulation nor renucleation.

The clay platelets were nicely dispersed in water in the form of non-aggregated elementary platelets. Indeed, dispersion of clay in water (without latex) was investigated by different methods (see Supporting Information). In short, conductimetry indicated full dispersion in $1 \mathrm{~h}$ and no aging via the release of lithium and magnesium ions after 4 days at ambient temperature, thus showing the time period during which the non-aggregated dispersion can be safely used for polymerization; TEM images combined to image analysis as well as cryo-TEM indicated that the dispersion contained only few stacks of two to six platelets, with an interlayer thickness of $1 \mathrm{~nm}$.

The coverage of the polymer particles surface by clay platelets was calculated as the ratio of the surface area of platelets' faces discs of $30 \mathrm{~nm}$ diameter to the polymer particles' area assuming spherical shape and full clay dispersion (see Supporting Information). For clay concentrations higher than $0.5 \mathrm{~g} \mathrm{~L}^{-1}$, the area of platelets was enough to cover the total surface area of particles and a significant excess of clay platelets was present at the beginning of the polymerization (Figure 1d). As the particles grew, this amount became insufficient to cover the full polymer particles' surface area, except with $10 \mathrm{~g} \mathrm{~L}^{-1}$ clay. These results suggest successful clay adsorption 
on the polymer particles' surface to ensure latex stability whatever the clay content. However, clay partitioning between the latex surface and water cannot be evaluated from these data.
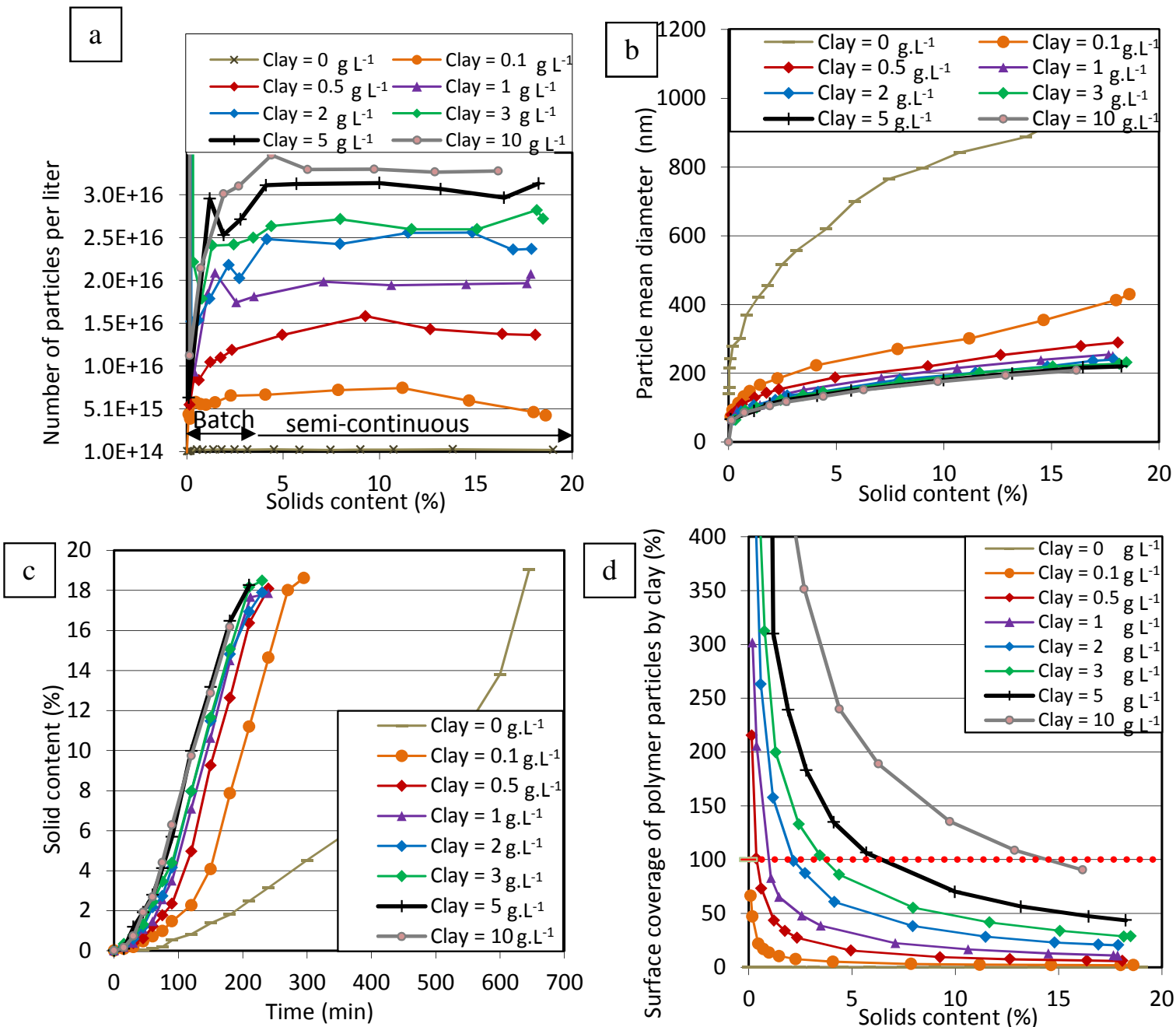

Figure 1. Results of the Pickering ab initio semi-continuous emulsion polymerization of styrene stabilized with different amounts of Laponite RDS ${ }^{\circledR}$. 


\subsubsection{Effect of clay concentration in seeded emulsion polymerization experiments}

These experiments are meant to evaluate the adsorption dynamics of clay on a previously produced clay-armored seed (containing $1 \mathrm{~g} \mathrm{~L}^{-1}$ of clay) and to assess the possible re-nucleation of polymer particles at high clay concentrations.

Two series of experiments were carried out with different clay concentrations, by allowing the clay to equilibrate in the latex for $1 \mathrm{~h}$ or $12 \mathrm{~h}$ before the reaction. Interestingly, both series gave similar results, which indicated fast adsorption of the clay (less than one hour under the considered experimental conditions: diluted latex at ambient temperature).
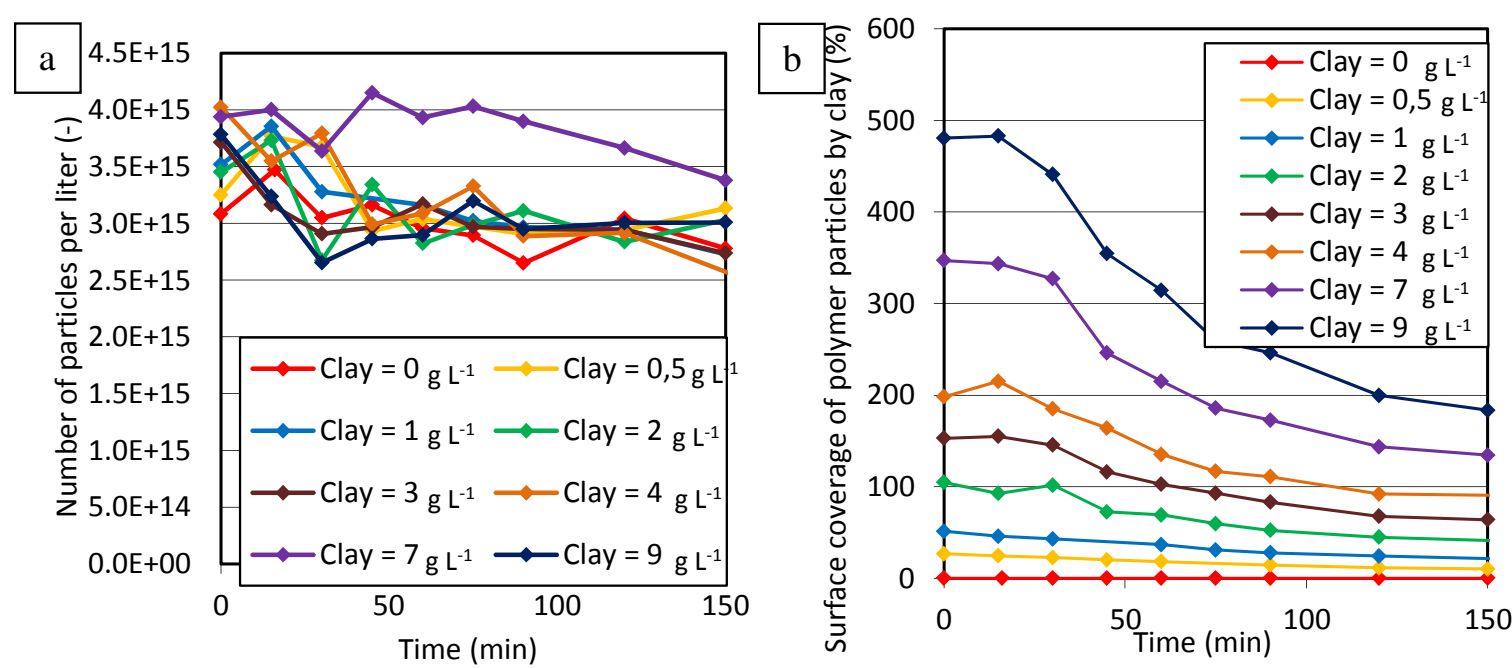

Figure 2. (a) Evolution of particle number in seeded semi-continuous emulsion polymerization with different amounts of clay, using an initial seed of $5 \mathrm{wt} \%$ solids content containing $1 \mathrm{~g} \mathrm{~L}^{-1}$ clay. (b) Ratio of the platelets area to the particles' area $(\times 100)$.

Figure 2 shows that the number of particles remained constant, after a slight reduction at the beginning of the polymerization, which reveals that the latex particles remained stable and that no further nucleation of polymer particles occurred. The seed particles grew from $280 \mathrm{~nm}$ to 
$470 \mathrm{~nm}$ by the end of the reaction. For all clay concentrations higher than $2 \mathrm{~g} \mathrm{~L}^{-1}$, the area of platelets was higher than that of polymer particles, which should allow total coverage in case of complete adsorption. If only one layer of clay is adsorbed, there should remain a large excess of residual clay platelets in water. However, no renucleation took place in these experiments. Note that in conventional emulsion polymerization in the presence of surfactants instead of clay, renucleation is possible in seeded experiments upon the addition of high amounts of surfactant that favor the nucleation of new particles at the expense of entry of waterborne oligoradicals into existing seeds; either due to micellar or homogeneous nucleation depending on the concentration of surfactant and solubility of monomer in water. The absence of renucleation suggests that the added clay is predominantly adsorbed on the polymer particles' surface, more precisely forming multilayers, and that no significant excess remains in water. This issue is addressed in the second part of the paper dealing with the characterization of the final latexes.

\subsubsection{Studying clay adsorption during polymerization using EDS}

The latex obtained by the end of a typical batch emulsion polymerization reaction in the presence of $1 \mathrm{wt} \%$ Laponite ${ }^{\circledR}$ RDS was analyzed by TEM. A thin light contour can be observed around the polystyrene particles indicating that clay platelets are located on the surface of the polymer particles (Figure 3a). An area in this image was selected for EDS analysis (enclosed by an ellipse) and the results are shown in Figure 3b. Two peaks corresponding to the carbon shell and three other peaks corresponding to oxygen, magnesium and silicon elements, respectively, revealed the presence of clay platelets around the polymer particles through the detection of magnesium and silicon in the selected area. The analysis also revealed the presence of copper probably originating from the TEM grid itself. 

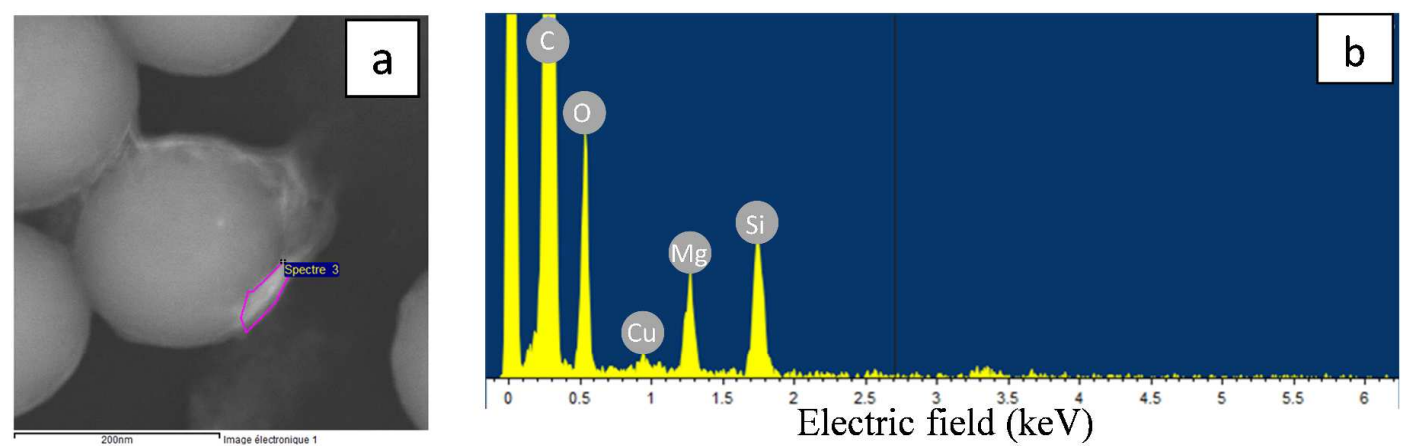

Figure 3.(a) Dark-field TEM image of polystyrene latex particles prepared in the presence of $1 \mathrm{wt} \%$ Laponite $^{\circledR}$ coupled with EDS analysis (scale bar: $200 \mathrm{~nm}$ ). (b) Intensity of element signal in EDS analysis.

The mapping of carbon, silicon and magnesium elements as measured by EDS is shown in Figure 4. The sample was scanned several times to create digital images for each element. The carbon map corresponds to polymer particles while the silicon and magnesium maps are related to the clay.

In Figure 4 silicon appears tightly bound to the particles surface while a small amount of magnesium is present in the aqueous phase. This might be due to $\mathrm{Mg}^{2+}$ ions leaching that was not completely avoided during polymerization at $70^{\circ} \mathrm{C}$ or during sample preparation. Note that polymerization took place under nitrogen starting at $\mathrm{pH} 8.8$ and reaching $\mathrm{pH} 8.2$ by the end of the reaction due to KPS decomposition. A rough estimate of the thickness of the clay coating is 10-20 nm. In all cases, the maps of silicon are more reliable; they reveal that the clay is mainly present on the surface of the latex particles and that the thickness of the layer of adsorbed clay is larger than the thickness of the elementary clay platelets. 


\subsubsection{Clay adsorption during polymerization using TEM}
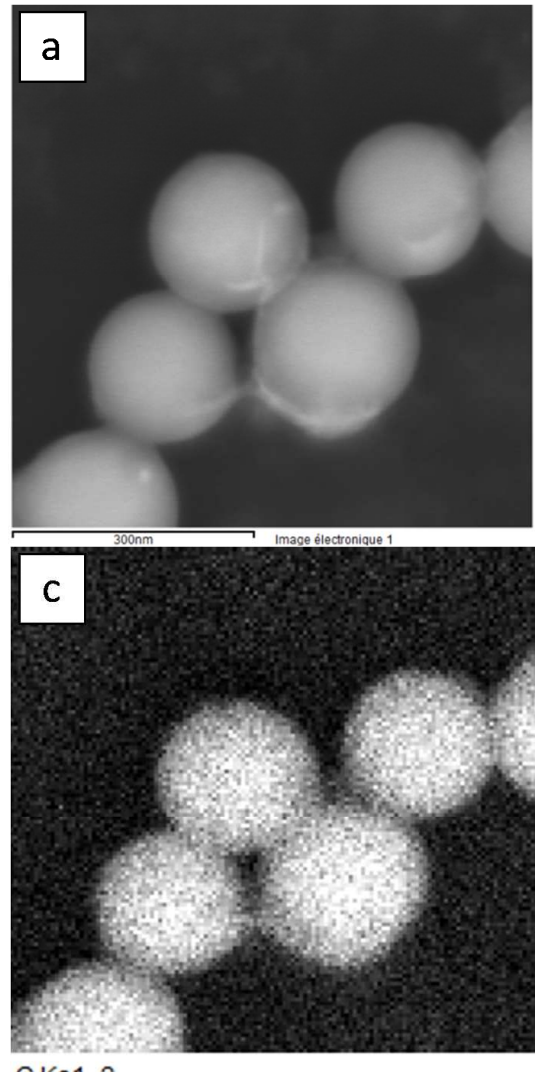

CKa1_2

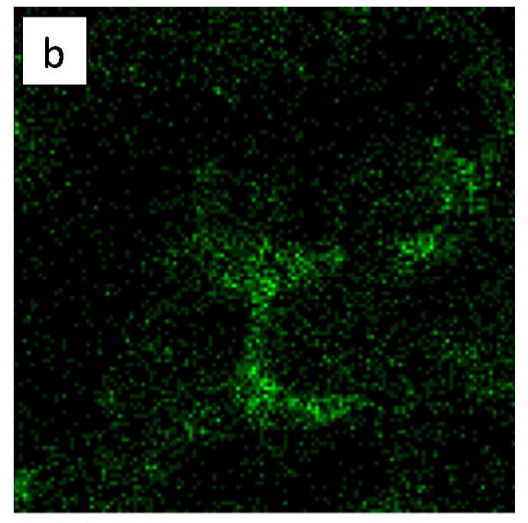

Ma Ka1 2

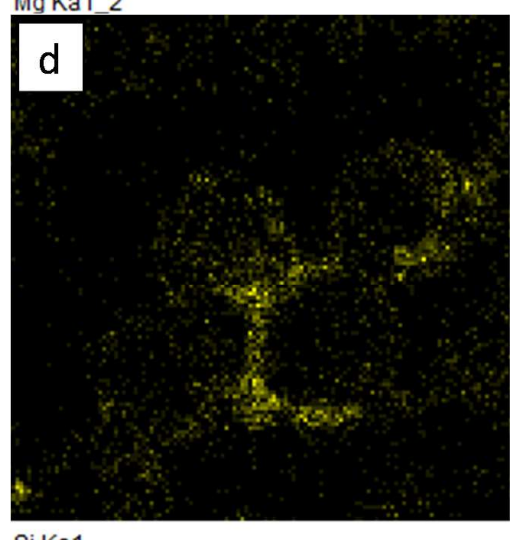

Si Ka1

Figure 4. a) Dark-field TEM image of polystyrene latex particles prepared in the presence of $1 \mathrm{wt} \%$ Laponite $^{\circledR}$ (the same latex as in Figure 3) (scale bar $=300 \mathrm{~nm}$ ). b-d) EDS analysis of the TEM image for silicon, carbon and magnesium, respectively.

Evidence for the formation of multilayers of clay platelets on the surface of the polymer particles during surfactant-free emulsion polymerization in the presence of clay was provided by TEM (Figure 5). Note that full exfoliation of the initial clay dispersions was supported by cryo-TEM analysis (see Supporting Information). Clay platelets are visible as black lines of about $1 \mathrm{~nm}$ thickness and $20 \mathrm{~nm}$ length. Stacks of platelets are formed on the surface of particles. Clay platelets also form bridges between the particles. 

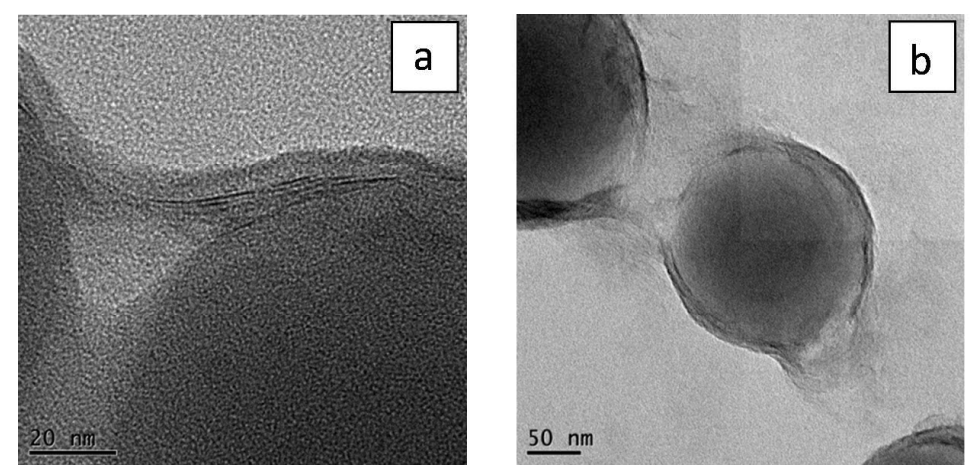

Figure 5. TEM images of polystyrene latex particles prepared in the presence of $1 \mathrm{wt} \%$ Laponite $^{\circledR}$ (the same latex as in Figure 3. a) Scale bar $=20 \mathrm{~nm}$. b) Scale bar $=50 \mathrm{~nm}$.

\subsection{Adsorption of Laponite ${ }^{\circledR}$ on surfactant-free polystyrene latex particles}

Partitioning of clay between water and the surface of polystyrene particles was studied in order to: i) establish whether initially fully exfoliated clay platelets in water subsequently adsorb on the particles surface as multilayers; ii) assess the interaction between clay and polystyrene surfaces and the effect of ionic strength on clay/polymer interaction, and iii) evaluate the residual amount of clay in water. A model of adsorption is sought from these analyses. Three different techniques were used: QCM, conductivity and ICP-AES. Note that a pure polystyrene cell was used for QCM study and a cleaned latex for the conductivity study, in order to assess the affinity between the clay and polystyrene, while both cleaned (adjusted to different ionic strengths) and uncleaned polystyrene latexes were used for the ICP-AES study in order to investigate the adsorption of clay on polystyrene as a function of ionic strength.

\subsubsection{Quartz crystal microbalance with dissipation (QCM-D)}

QCM-D was used to monitor the adsorption of Laponite ${ }^{\circledR}$ RDS onto the surface of a commercial polystyrene cell, using two concentrations of Laponite ${ }^{\circledR}$ RDS in water: $2 \mathrm{~g} \mathrm{~L}^{-1}$ and $10 \mathrm{~g} \mathrm{~L}^{-1}$. 
60
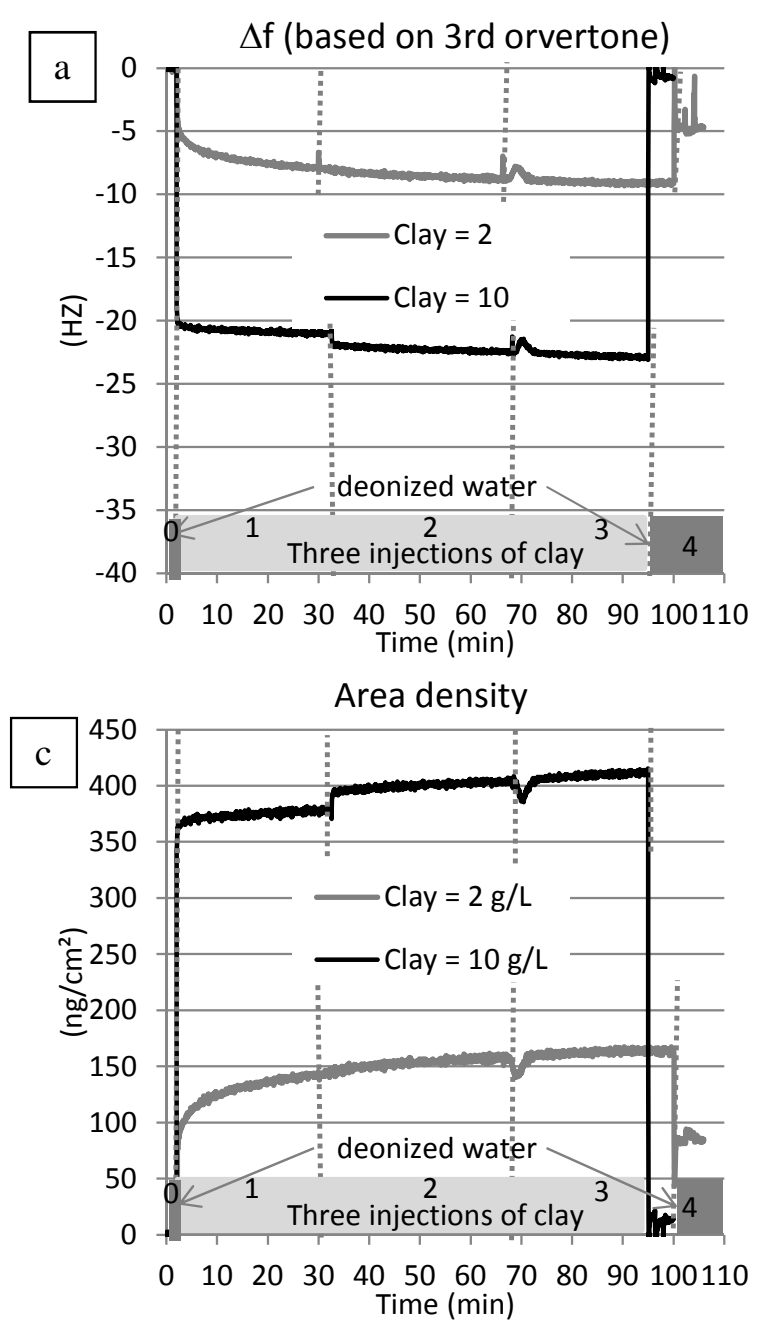
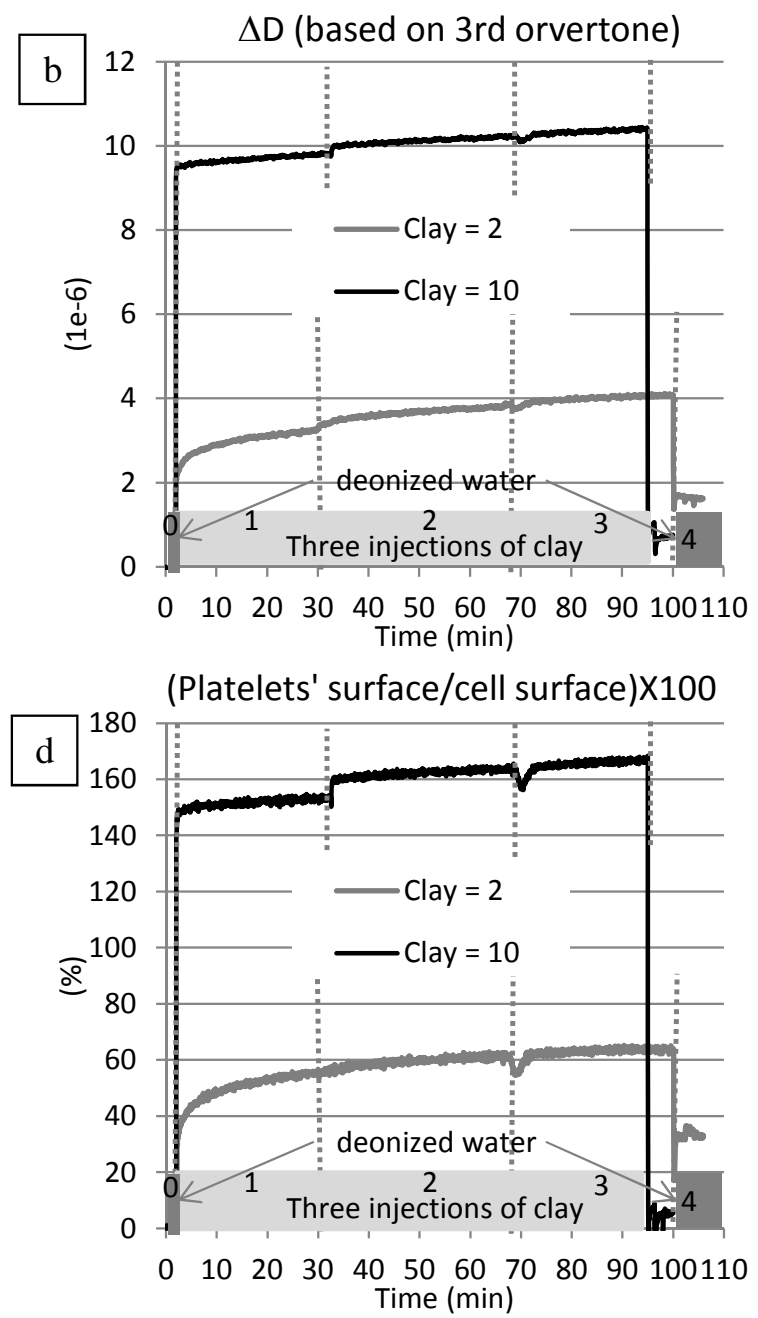

Figure 6. QCM resonance frequency and dissipation energy results, and calculated surface density and surface coverage, with a $2 \mathrm{~g} \mathrm{~L}^{-1}$ and $10 \mathrm{~g} \mathrm{~L}^{-1}$ aqueous dispersions of Laponite ${ }^{\circledR} \mathrm{RDS}$.

Figure 6 shows the QCM results, calculated from the third overtone measurements, selected for its better signal-to-noise ratio. The frequency shift (Figure 6a) was measured as a function of time: first deionized water was introduced in order to establish a stable baseline after about 2 min (step 0); The steps named 1, 2 and 3 corresponded to a new injection of fresh clay dispersion; Finally, rinsing was applied in order to evaluate the adhesion strength of adsorbed clay on the surface (step 4). The high shift of the resonance frequency since the $1^{\text {st }}$ pass (start of step 1) 
indicates a fast Laponite ${ }^{\circledR}$ RDS adsorption on polystyrene, which reveals a strong affinity with the polystyrene surface. Since the polystyrene surface did not receive a surface modification, the polystyrene cell surface was neutral, which precludes the possibility of charge interactions. Adsorption was thus due to non-electrostatic interactions. The fast adsorption indicates a weak energy barrier against adsorption. Clay adsorption was not due to sedimentation since it has been checked that the injected clay dispersions were stable and did not show sedimentation over the time range of the QCM experiments.

At each new injection of the high clay concentration of $10 \mathrm{~g} \mathrm{~L}^{-1}$ (steps 2 and 3), the frequency stabilized quickly, whereas the frequency continued to decrease slightly as a function of time and did not reach a stationary value after addition of the lower clay concentration of $2 \mathrm{~g} \mathrm{~L}^{-1}$. This indicates a slow and continuous adsorption from the dilute dispersion of Laponite ${ }^{\circledR}$. When deionized water was used for rinsing after the adsorption study (step 4), all the clay was released into water for the concentration of $10 \mathrm{~g} \mathrm{~L}^{-1}$, while a small but significant amount remained anchored for the concentration of $2 \mathrm{~g} \mathrm{~L}^{-1}$. This indicates that the link between the clay and polystyrene is not permanent. Also, there might be different kinds of arrangements of the clay, where non-organized and less dense configurations might be released more easily. In this case, highly concentrated dispersions seem to lead to the formation of such non-organized layers.

In order to calculate the mass of adsorbed material $(\Delta m)$ from the measured frequency shift $(\Delta f)$, different correlations were proposed in the literature ${ }^{22}$. The measured resonance frequencies divided by their overtone number were identical for the three measured harmonics in our case, showing that the adsorbed layer was rigid, which allows using the relationship of Sauerbrey ${ }^{34}$ : 


$$
\Delta m=-A \underbrace{\left(\frac{\sqrt{\mu \rho_{q}}}{2 f_{0}^{2}}\right)}_{C} n \Delta f
$$

where $n$ is the overtone number, $A=1.54 \mathrm{~cm}^{2}$ the electrode area and $C$ the mass sensitivity constant. Using the intrinsic crystal frequency $f_{0}=5 \mathrm{mHz}$, the quartz density $\rho_{q}=2.65 \mathrm{~g} \mathrm{~cm}^{-3}$ and its shear modulus $\mu=2.95 \times 10^{10} \mathrm{~N} \mathrm{~m}^{-2}$, one gets $C=17.7 \mathrm{ng} \mathrm{cm}^{-2} \mathrm{~Hz}^{-1}$. Note that this equation is valid for rigid, non-slip, evenly distributed and sufficiently thin adsorbed layers such that the vibration is completely coupled to the oscillating crystal, ensuring a linear relationship between the adsorbed mass and the frequency. For soft or viscoelastic films causing energy loss during oscillation, both the frequency and the dissipation should be considered in order to calculate the mass, using for instance the Voigt viscoelastic model, or the Kanazawa and Cordon's expression ${ }^{35}$.

The calculated surface density of clay platelets is given in Figure 6c. A higher adsorption level was reached instantaneously since the $1^{\text {st }}$ injection for the $10 \mathrm{~g} \mathrm{~L}^{-1}$ clay suspension $\left(375 \mathrm{ng} \mathrm{cm}^{-2}\right)$ compared to the $2 \mathrm{~g} \mathrm{~L}^{-1}$ dispersion $\left(100 \mathrm{ng} \mathrm{cm}^{-2}\right)$. Therefore, the adsorbed amount of clay increases when the concentration of clay in the dispersion is increased. The fast adsorption of clay for both concentrations (of the order of minutes), is favorable to emulsion polymerization in view of the requirement of a fast stabilization of polymer particles.

The area covered by the platelets was estimated from the adsorbed mass of clay divided by the polystyrene cell surface $\left(1.54 \mathrm{~cm}^{2}\right)$ (Figure 6d). As QCM determines the mass of the adsorbed film including trapped solvent, it is necessary to estimate the mass of adsorbed water. The measured water content in the dry powder was $10 \mathrm{wt} \%$ and water interlayer measured in the suspension was $0.35 \mathrm{~nm}$ (see Supporting Information), which gives a clay surface density of $35 \mathrm{ng} \mathrm{cm}^{-2}$ per layer. As the number of layers is not known, the surface coverage was first 
calculated without eliminating the water interlayer mass. Figure $6 \mathrm{~d}$ shows the ratio of the calculated clay platelets' area to the cell surface. This value can be considered as the surface coverage, under the assumption that the clay platelets lay flat on the cell surface and that adsorption is not limited by steric hindrance. In all cases, the calculation remains indicative, and it can be seen that the adsorbed amount of clay does not allow saturation of the polystyrene cell surface for the $2 \mathrm{~g} \mathrm{~L}^{-1}$ suspension while the surface was saturated at higher concentration. The observed incomplete coverage at $2 \mathrm{~g} \mathrm{~L}^{-1}$ clay justifies the continuous increase in the adsorbed amount without reaching equilibrium for the lower clay concentration. With the high clay concentration, overlapping or multilayer formation of clay platelets on the surface seems to take place. Part of the formed layers might be due to the non-exfoliated fraction of the clay, as observed by TEM (see Supporting Information).

The configuration of adsorption and structural (viscoelastic) properties of the adsorbed material can be assessed from the energy dissipation (Figure 6b). The dissipation followed a similar behavior as the frequency shift, which indicated that the adsorbed particles were firmly stuck to the surface. Indeed, clay particles extending out into the aqueous solution as non-organized layers would increase the dissipation without affecting the frequency ${ }^{22}$. The few works dealing with clay adsorption on solid surfaces, mainly focused on electrostatic interactions because surfaces were coated with cationic polymers such as poly(diallyldimethylammonium chloride), thus giving a higher adsorption and variations of resonance frequency by QCM..$^{22,36-39}$

It is first concluded that Laponite ${ }^{\circledR}$ adsorption on neutral polystyrene takes place even though there is no surface charge. This indicates that non-electrostatic interactions between the clay and the polystyrene surface are operating. Secondly, multilayers of platelets can form on the polymer 
surface. Finally, the adsorption time measured by QCM is much shorter than the duration of the nucleation period in this Pickering emulsion polymerization process.

\subsubsection{Conductivity measurements}

Partitioning of clay platelets between water and the particles surface was assessed by means of electrical conductivity measurements of suspensions of cleaned surfactant-free seed lattices of three different diameters: 200,400 and $750 \mathrm{~nm}$ to which the clay dispersion was added. The measured conductivity was therefore mainly due to charged species related to the addition of clay, as free ionic species coming from the initiator were removed during the cleaning process. Moreover, the contribution to the conductivity of $\mathrm{Mg}^{2+}$ ions released from the edges of Laponite ${ }^{\circledR}$ platelets is relatively small ${ }^{40}$. This was confirmed by the conductivity of aqueous clay dispersions (without latex) that remained constant over 4 days, which indicated no $\mathrm{Mg}^{2+}$ ions leaching during the measurements (see Supporting Information). Note also that the peptizing agent eliminates rim charges of Laponite ${ }^{\circledR}$. Therefore, the main source of conductivity during the first days is $\mathrm{Na}^{+}$counterions released from the Laponite ${ }^{\circledR}$ into solution.

Figure 7. shows the measured conductivity for latexes containing different amounts of Laponite ${ }^{\circledR}$ compared to the conductivity of pure aqueous Laponite ${ }^{\circledR}$ dispersions (without latex). The conductivity of clay in the latex was lower than that of the aqueous clay dispersion, which indicates clay adsorption on the polymer particles. Moreover, the higher the particles' surface area, the lower was the conductivity. Finally, the variation of conductivity was linear with respect to the concentration of clay indicating that the mobility of $\mathrm{Na}^{+}$ions was maintained identical at the different concentrations and the added clay had the same degree of exfoliation. 


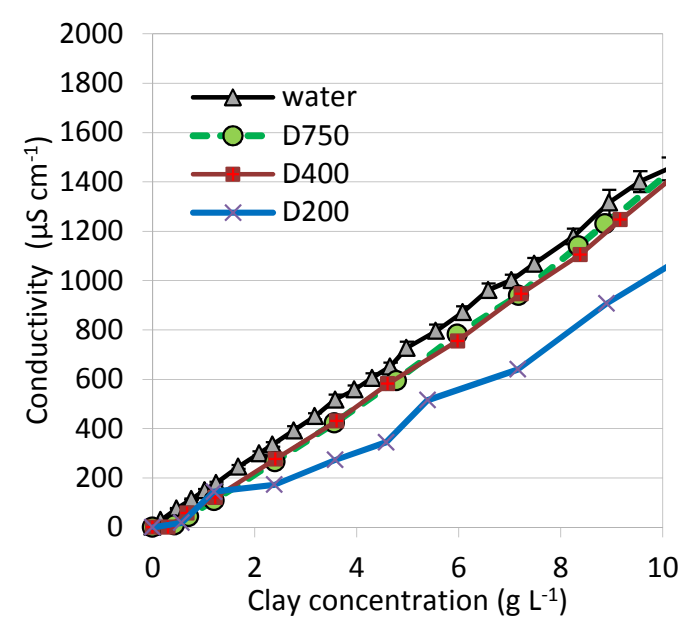

Figure 7. Conductivity of Laponite ${ }^{\circledR}$ suspensions in pure water and in latex suspensions (5 wt $\%$ in water) for three different latex particles diameters, $D=200,400$ and $750 \mathrm{~nm}$ as a function of clay concentration.

\subsubsection{Inductively Coupled Plasma-Atomic Emission Spectroscopy (ICP-AES)}

In order to collect supplementary quantitative data to the previous investigations, clay partitioning between water and the surface of polymer particles was investigated using quantitative ICP-AES analyses of silicon. The concentration of clay in the aqueous phase was measured following two separation techniques: centrifugation or filtration, where both methods gave identical results (for 3 replicates). The surfactant-free seed latex with a mean diameter of $400 \mathrm{~nm}$ was used under three conditions: after cleaning the latex, without cleaning, and using cleaned latex with added $\mathrm{KCl}$ salt to adjust the ionic strength $\left(0.12,0.2\right.$ and $\left.0.29 \mathrm{~mol} \mathrm{~L}^{-1}\right)$. The uncleaned latex allowed studying clay adsorption under the same ionic strength conditions as during the polymerization, i.e. including sulfate anions resulting from initiator decomposition. The cleaned latex allowed evaluating the adsorption rate of clay on pure polystyrene and thus 
comparison with QCM and conductivity studies. Finally, the cleaned latex with adjusted ionic strength allowed discriminating the effect of the ionic strength.
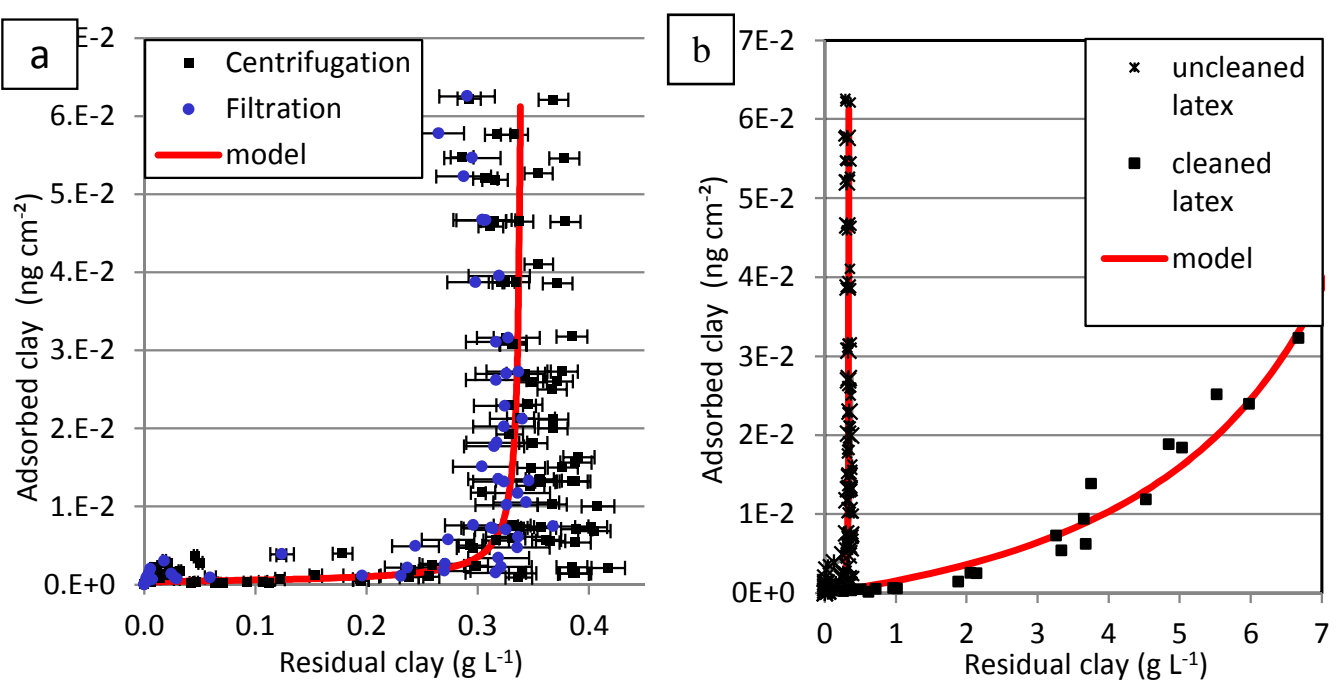

Figure 8. Adsorption isotherm of Laponite ${ }^{\circledR}$ on polystyrene latex particles ( $5 \mathrm{wt} \%$ solids content and mean diameter $400 \mathrm{~nm}$ ) measured using $\mathrm{Si}$ analysis by ICP-AES a) uncleaned latex (using centrifugation and filtration methods); b) both cleaned and uncleaned lattices. The measurements are compared to the adsorption isotherm model.

Adsorption isotherms of Laponite were obtained from ICP-AES analyses of the Si element as Si is the major component of Laponite ${ }^{\circledR}(23.3 \%)$. The Li content is only $0.3 \%$ of Laponite ${ }^{\circledR}$, so Li analysis provides a lower accuracy than $\mathrm{Si} . \mathrm{Mg}^{2+}$ ions (14.3\%) might slightly leach into water and therefore cannot be used to evaluate clay adsorption. The adsorption isotherm of the uncleaned latex (Figure 8 a) shows two distinct adsorption regimes as a function of the clay concentration: first a coexistence of adsorbed clay particles and residual particles in aqueous suspension was observed for clay concentrations lower than $0.34 \mathrm{~g} \mathrm{~L}^{-1}$. Here, the adsorbed amount was lower (as calculated below) than the amount allowing full coverage of the polymer surface; Above this clay concentration, the adsorption isotherm was almost vertical, showing that 
clay particles in excess to $0.34 \mathrm{~g} \mathrm{~L}^{-1}$ in water $\left(1.5 \mathrm{~g} \mathrm{~L}^{-1}\right.$ in total) fully adsorbed onto the latex particles. Here, the adsorbed amount exceeds the limit of a dense monolayer. Such results strongly suggest that the clay is adsorbing as a monolayer for concentrations lower than $0.34 \mathrm{~g} \mathrm{~L}^{-}$ ${ }^{1}$ and forms multilayers for higher concentrations. Therefore, the residual concentration of clay in water cannot be increased. It is important to emphasize that the same mother clay dispersion was used to perform all the ICP-AES experiments, which means that the clay platelets had the same initial degree of dispersion. Moreover, conductometric measurements have shown a linear relationship between the conductivity and the clay concentration, indicating no (or identical) formation of aggregates as a function of the concentration. Therefore, the formation of multilayers cannot be attributed to increased aggregated stacks formed in water upon increasing the clay concentration. Rather, the clay looks well-exfoliated in water in all cases, but stacks as multilayers on the surface of the particles during their adsorption.

Figure $8 \mathrm{~b}$ shows the adsorption results for the cleaned latex. It can be seen that the adsorption is less effective in this case, which indicates that the presence of initiator residues in the aqueous phase plays an important role in clay adsorption. The sulfate ions in solution lead to an increase in the ionic strength which screens the clay charge and enhances the adsorption to the surface of the negatively charged polystyrene latex. Note that multilayers formation is still taking place with the cleaned latex, but at a lower rate as a function of the clay concentration.

Since it was presumed that the strong adsorption as multilayers to the uncleaned latex was caused by the ionic strength, clay adsorption on the cleaned latex was investigated at different ionic strengths $\left(0.06,0.1\right.$, and $0.15 \mathrm{~mol} \mathrm{~L}^{-1}$ which led to conductivities of 15,25 , and $35 \mathrm{mS} \mathrm{cm}^{-}$ ${ }^{1}$, respectively) and compared to the results obtained for the uncleaned latex (Figure 9). The range of ionic strengths was chosen such as to be comparable to the ionic strength of the 
uncleaned latex by addition of a concentrated $\mathrm{KCl}$ solution to the cleaned latex until it attains the conductivity of the uncleaned latex $\left(35 \mathrm{mS} \mathrm{cm}^{-1}\right)$. Intermediate ionic strengths corresponding to lower conductivities were also tested. Note that the latex did not coagulate upon the addition of $\mathrm{KCl}$ in the studied samples, as the particle size measured after the addition of $\mathrm{KCl}$ remained unchanged. Moreover, the latex did not reach a visible gel state although the addition of $\mathrm{KCl}$ to clay dispersions (without polymer particles) was found to promote gelation (as validated by Nano-ZS size measurements). This supports the assumption that a majority of clay was adsorbed on the particle surface and that only a minor amount remained free in suspension.

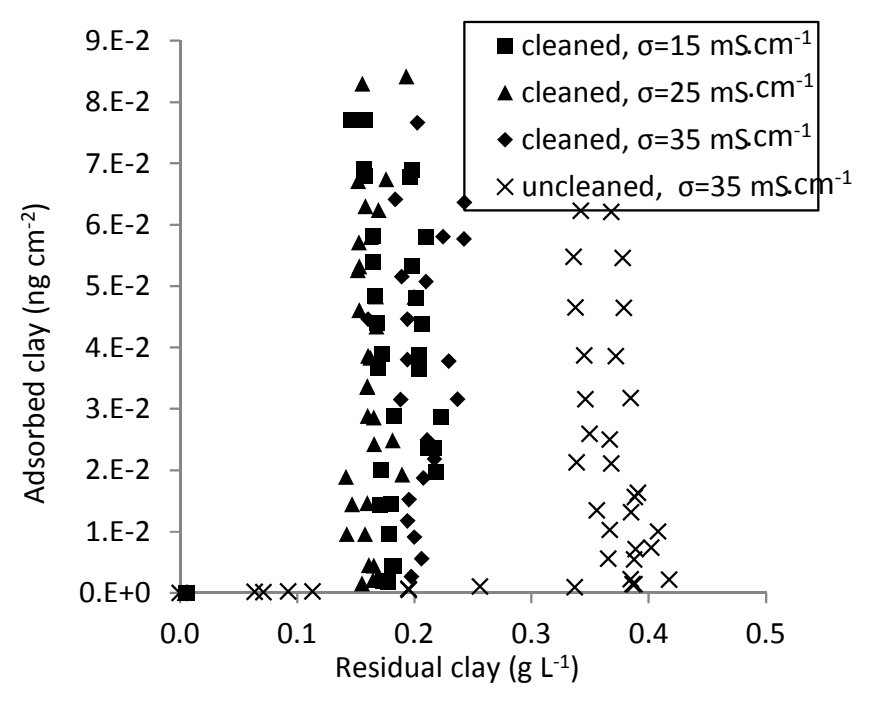

Figure 9. Adsorption isotherm of Laponite ${ }^{\circledR}$ on polystyrene latex particles (5 wt \% solids content and mean diameter $300 \mathrm{~nm}$ ) measured using ICP-AES analyses of $\mathrm{Si}$, for the uncleaned latex $(\sigma$ $=35 \mathrm{mS} \mathrm{cm}^{-1}$ ) as well as cleaned latex adjusted to different ionic strengths by addition of $\mathrm{KCl}$.

Figure 9 shows that the addition of salt to the cleaned latex led to an adsorption profile comparable to that of the uncleaned latex, which confirms that the screening effect by the ions in the medium is at the origin of enhanced clay adsorption in the uncleaned latex. A slightly higher 
adsorption rate was however measured in the presence of $\mathrm{KCl}$ compared to the uncleaned latex for a similar ionic strength. It is also noticeable that the majority of the clay introduced was adsorbed on the particle surface whatever the amount of salt introduced with the range of ionic strengths investigated.

It is therefore concluded that during emulsion polymerization, adsorption of clay on polymer particles is due to non-electrostatic attractions with the polymer, possibly dispersion forces, which are predominant when electrostatic repulsions have been weakened by the high ionic strength. The stabilization of polymer particles by adsorbed clay platelets is probably caused by the formation of a rigid crust around the polymer particles that prevent their coalescence. This is the main mechanism put forward for the stabilization of Pickering emulsions. ${ }^{41,42}$ Moreover, almost full exfoliation of the clay in water is demonstrated, so that multilayer formation on the surface of the polymer latex particles is not due to clay aggregation in water, but to progressive adsorption to the polymer particles surface. The results for the cleaned latex can be compared to the QCM experiments described above (similar ionic strength). For the clay concentration of $2 \mathrm{~g} \mathrm{~L}^{-1}$, similar results were obtained by QCM and ICP: an adsorbed amount of clay of $1.5 \times 10^{-}$ ${ }^{3} \mathrm{~g} \mathrm{~m}^{-2}$ (corresponding to $60 \%$ surface coverage). For the clay concentration of $10 \mathrm{~g} \mathrm{~L}^{-1}$, the adsorbed amount of clay measured by QCM was lower, $4 \times 10^{-3} \mathrm{~g} \mathrm{~m}^{-2}$ (160\% surface coverage) than by ICP, $1.5 \times 10^{-2} \mathrm{~g} \mathrm{~m}^{-2}$ (600\% surface coverage). But, in both cases multilayer adsorption was detected. 


\subsubsection{Modelling clay adsorption based on ICP-AES}

Different models have been proposed in the literature to describe adsorption phenomena. The Langmuir isotherm was first developed to describe gas-solid adsorption, assuming monolayer adsorption with no lateral interactions or steric hindrance between the adsorbed molecules: ${ }^{37}$

$$
\frac{q}{q_{m}}=\frac{K_{S} C_{e q}}{1+K_{S} C_{e q}}
$$

where $C_{e q}\left(\mathrm{~g} \mathrm{~L}^{-1}\right)$ is the equilibrium solution concentration, $q\left(\mathrm{mg} \mathrm{m}^{-2}\right)$ the surface density of adsorbed species, $q_{m}\left(\mathrm{mg} \mathrm{m}^{-2}\right)$ the adsorbed amount at the plateau (maximum surface density for monolayer coverage) and $K_{S}$ the associated equilibrium constant.

For multilayer adsorption, the Brunauer-Emmett-Teller (BET) isotherm is the most widely used $^{44}$. It allows describing monolayer and multilayer adsorption behaviors. The concept of the theory is an extension of the Langmuir theory under the additional hypothesis that molecules can also physically adsorb by binding to already adsorbed molecules, resulting in the formation of multilayers with no limit regarding the number of layers. This model was originally developed for adsorption from the gas phase:

$$
\frac{q}{q_{m}}=\frac{c x}{(1-x)(1-x+c x)}
$$

where $x$ is the ratio of the partial pressure of the adsorbate to its saturation partial pressure at the system temperature and $q_{m}$ is the surface density of adsorbed species for a hypothetic monolayer at full coverage. $c$ is the BET constant defined as $c=\exp \left(\frac{E_{1}-E_{N}}{k_{B} T}\right)$ where $E_{1}$ is the heat of adsorption for the first layer and $E_{N}$ is that for the second and higher layers. The BET model was then applied to liquid phase adsorption by substituting the partial pressure of the adsorbate by its 
concentration in the liquid phase ${ }^{45,46}$. Using equation 3 with $x=C_{e q} / C_{S}$ and $C_{S}$ is taken as an adjustable parameter, the equation has three degrees of freedom $\left(q_{m}, c, C_{S}\right)$ to be identified by regression to the experimental data. The BET isotherm was used to model the adsorption in this system as it is well-suited to account for multilayer adsorption. The fitted models' parameters are shown in Table 1 and the modelling results are superimposed to the experimental data in Figure 8. It can be seen that the model fits very well to the experimental data.

\begin{tabular}{|c|c|c|}
\hline Parameter & Uncleaned latex & Cleaned latex \\
\hline$q_{\mathrm{m}}\left(\mathrm{mg} \mathrm{m}^{-3}\right)$ & 6.0 & 8.0 \\
\hline$C_{\mathrm{s}}\left(m g \mathrm{~L}^{-1}\right)$ & $3.9 \times 10^{2}$ & $8.4 \times 10^{3}$ \\
\hline$c$ & 0.3 & 3.5 \\
\hline$K_{\mathrm{S}}$ & $9.2 \times 10^{-4}$ & $3.9 \times 10^{-4}$ \\
\hline$K_{\mathrm{L}}$ & $2.8 \times 10^{-3}$ & $1.1 \times 10^{-4}$ \\
\hline
\end{tabular}

Table 1. Parameters of the BET isotherm model applied for the adsorption of Laponite ${ }^{\circledR}$ on polystyrene particles (cleaned and uncleaned latexes).

In order to be able to estimate the adsorption energies corresponding to the different layers in adsorption from the liquid phase besides substituting the partial pressure of the adsorbate by the liquid phase concentration, Ebadi et al. $^{45}$ expressed the BET constant $c$ as the ratio of the equilibrium constants of the adsorption equilibria for the first layer and the higher layers: $c=\frac{K_{S}}{K_{L}}$, which leads to the following equation ${ }^{39,40}$ :

$$
\frac{q}{q_{\mathrm{m}}}=\frac{K_{S} C_{\mathrm{eq}}}{\left(1-K_{\mathrm{L}} C_{\mathrm{eq}}\right)\left[1-K_{\mathrm{L}} C_{\mathrm{eq}}+K_{\mathrm{S}} C_{\mathrm{eq}}\right]}
$$

where $K_{\mathrm{S}}$ is the adsorption equilibrium constant of the $1^{\text {st }}$ layer and $K_{\mathrm{L}}$ the adsorption equilibrium constant of upper layers. Upon the assumption $c=\frac{K_{S}}{K_{L}}$, which might be argued, the estimated $K_{S}$ 
and $K_{L}$ parameters in our experiments are shown in Table 1. It can be seen that the binding constant of Laponite ${ }^{\circledR}$ to the uncleaned latex surface, $K_{\mathrm{S}}$, is 3 times lower than the binding constant of Laponite ${ }^{\circledR}$ to the adsorbed Laponite ${ }^{\circledR}$ layers, $K_{\mathrm{L}}$, showing that the formation of multilayers takes place by means of stronger interactions in the upper layers than for the first layer contacting polystyrene. The order of $K_{\mathrm{S}}$ and $K_{\mathrm{L}}$ is reversed in the case of cleaned latex. $K_{\mathrm{S}}$ and $K_{\mathrm{L}}$ are both higher for the uncleaned latex than the cleaned one, indicating stronger adsorption to the uncleaned latex. Indeed electrostatic repulsions acting against adsorption are stronger for the salt-free cleaned latex. For the same reason, the clay concentration at the onset of multilayer formation by surface aggregation is also lower for the uncleaned latex than for the cleaned one. The ratio of the binding constants to the uncleaned and to the cleaned latex provides an estimate of the electrostatic contribution to the adsorption. Such ratio was 2.4 for the first layer and 25 for the higher layers, showing that the electrostatic phenomena give a larger contribution to the clay-clay than to the clay-polystyrene interactions in the adsorbed layer.

\section{Conclusions}

Laponite $^{\circledR}$ was found to play an important role in Pickering emulsion polymerization of styrene. It not only ensures stability of polymer particles and determines the number density of produced particles during the nucleation period, but it also controls the reaction rate. In seeded experiments, Laponite ${ }^{\circledR}$ ensures effective stabilization whatever the clay content, and no further nucleation of particles occurred even for very high clay concentrations.

In order to illustrate the role of clay and its partitioning between water and the surface of the polymer particles, different analysis techniques were used: QCM-D, conductometry and ICPAES. Using pure polystyrene, the three methods demonstrated that non-electrostatic attractions 
between the clay and polystyrene could overcome electrostatic repulsions in order to allow adsorption. Interestingly, multilayer adsorption of platelets on the polymer surface was demonstrated. ICP-AES measurements were also conducted on uncleaned latex, to mimic the emulsion polymerization conditions. A higher adsorption of clay on the polymer particles was measured in this case, indicating an effect of ionic strength on adsorption due to its screening of the clay surface charges. This was confirmed by adjusting the ionic strength of a series of cleaned latexes by adding different amounts of $\mathrm{KCl}$, to reach an ionic conductivity similar to that of the uncleaned latex containing sulfate ions.

TEM and EDS analyses of clay-armored particles synthesized via surfactant-free emulsion polymerization showed that the clay was adsorbed as multilayers on the polystyrene particles, leading to a thick shell. The driving force for the formation of multilayers remains obscure. The present investigation has shown that the formation of multilayer doesn't require additional salt (multilayer was observed with QCM in pure water). This suggests that the formation of multilayers involves non-electrostatic contributions. But, adsorption is enhanced by higher ionic strength, showing that electrostatic interactions also matter. Aggregation of the clay platelets takes place specifically on the surface of the polymer particles and not in the bulk aqueous phase. These results show that any added clay adsorbs on the polymer particles and the concentration in the aqueous phase remains constant. This prevents further nucleation of new polymer particles by the presence of clay in the suspension during seeded emulsion polymerization experiments.

The adsorption behavior was satisfactorily modelled using the BET isotherm, which confirms the hypothesis of multilayer adsorption with cooperative binding. The developed adsorption model will be of use for modelling and understanding the whole polymerization process. 


\section{Acknowledgement}

This work was funded by Agence Nationale de la Recherche grant n ANR-12-JS09-0007-01.

\section{References}

(1) Piao, S. H.; Kwon, S. H.; Zhang, W. L.; Choi, H. J. Celebrating Soft Matter's 10th Anniversary: Stimuli-responsive Pickering emulsion polymerized smart fluids. Soft Matter 2014, 11 (4), 646-654.

(2) Sill, K.; Yoo, S.; Emrick, T. Polymer-Nanoparticle Composites. In Dekker Encyclopedia of Nanoscience and Nanotechnology, Second Edition; Taylor \& Francis, 2009; pp 3487-3500.

(3) Sheibat-Othman, N.; Bourgeat-Lami, E. Use of Silica Particles for the Formation of Organic-Inorganic Particles by Surfactant-Free Emulsion Polymerization. Langmuir 2009, 25 (17), 10121-10133.

(4) Alexandre, M.; Dubois, P. Polymer-layered silicate nanocomposites: preparation, properties and uses of a new class of materials. Mater. Sci. Eng. Chem: R: Reports 2000, 28 (1), $1-63$.

(5) Fang, F. F.; Kim, J. H.; Choi, H. J. Synthesis and electrorheological response of nanosized laponite stabilized poly(methyl methacrylate) spheres. Colloid Polym. Sci. 2009, 754-749.

(6) Kim, Y. J.; Liu, Y. D.; Choi, H. J.; Park, S.-J. Facile fabrication of Pickering emulsion polymerized polystyrene/laponite composite nanoparticles and their electrorheology. J. Colloid Interface Sci.2013, 394, 108-114 DOI: 10.1016/j.jcis.2012.12.040.

(7) Bon, S. A.; Colver, P. J. Pickering Miniemulsion Polymerization Using Laponite Clay as a Stabilizer. Langmuir 2007, 8316-8322.

(8) Sheibat-Othman, N.; Cenacchi-Pereira, A.-M.; Santos, A. M. D.; Bourgeat-Lami, E. A kinetic investigation of surfactant-free emulsion polymerization of styrene using laponite clay platelets as stabilizers. J. Polym. Sci. A Polym. Chem. 2011, 49, 4771-4784.

(9) Xu, Y.; Higgins, B.; Brittain, W. J. Bottom-up synthesis of PS-CNF nanocomposites. Polym. 2005, 46, 799-810.

(10) Sherman, R. L.; Ford, W. T. Small Core/Thick Shell Polystyrene/Poly(methyl methacrylate) Latexes. Ind. Eng. Chem. Res. 2005, 44, 8538-8541.

(11) Caruso, R. A.; Susha, A.; Caruso, F. Multilayered Titania, Silica, and Laponite Nanoparticle Coatings on Polystyrene Colloidal Templates and Resulting Inorganic Hollow Spheres. Chem. Mater. 2001, 400-409.

(12) Sun, Q.; Deng, Y.; Wang, Z. L. Synthesis and Characterization of PolystyreneEncapsulated Laponite Composites via Miniemulsion Polymerization. Macromol. Mater. Eng. 2004, 289, 288-295.

(13) Bourgeat-Lami, E.; Sheibat-Othman, N.; Dos Santos, A. M. Polymer-Clay Nanocomposite Particles and Soap-free Latexes Stabilized by Clay Platelets: State of the Art and Recent Advances. In Polymer Nanocomposites by Emulsion and Suspension; Mittal, V., Ed.; RSC Publishing, 2010; pp 269-311.

(14) Ruggerone, R.; Plummer, C. J.; Herrera, N. N.; Bourgeat-Lami, E.; Manson, J. A. E. Mechanical properties of highly filled latex-based polystyrene/laponite nanocomposites. In Solid 
State Phenomena; Trans Tech Publ, 2009; Vol. 151, pp 30-34.

(15) Negrete-Herrera, N.; Letoffé, J.-M.; Putaux, J.-L.; David, L.; Bourgeat-Lami, E. Aqueous Dispersions of Silane- unctionalized Laponite Clay Platelets. A First Step toward the Elaboration of Water-Based Polymer/Clay Nanocomposites. Langmuir 2004, 1564-1571.

(16) Negrete-Herrera, N.; Putaux, J.-L.; Bourgeat-Lami, E. Synthesis of polymer/Laponite nanocomposite latex particles via emulsion polymerization using silylated and cation-exchanged Laponite clay platelets. Prog. Solid State Chem. 2006, 34 (2), 121-137.

(17) Negrete-Herrera, N.; Putaux, J.-L.; David, L.; Haas, F. D.; Bourgeat-Lami, E. Polymer/Laponite composite latexes: Particle morphology, film microstructure, and properties. Macromol. Rapid Commun. 2007, 28, 1567-1573.

(18) Negrete-Herrera, N.; Putaux, J.-L.; David, L.; Bourgeat-Lami, E. Polymer/Laponite Composite Colloids through Emulsion Polymerization: Influence of the Clay Modification Level on Particle Morphology. Macromolecules 2006, 39, 9177-9184.

(19) Ruggerone, R.; Plummer, C. J.; Herrera, N. N.; Bourgeat-Lami, E.; M $\backslash a$ anson, J.-A. E. Highly filled polystyrene-laponite nanocomposites prepared by emulsion polymerization. Eur. Polym. J. 2009, 45 (3), 621-629.

(20) Negrete-Herrera, N.; Persoz, S.; Putaux, J.-L.; David, L.; Bourgeat-Lami, E. Synthesis of polymer latex particles decorated with organically-modified laponite clay platelets via emulsion polymerization. J. Nanosci. Nanotechnol. 2006, 6, 421-431.

(21) Aranda, P.; Ruiz-Hitzky, E. New polyelectrolyte materials based on smectite polyoxyethylene intercalation compounds. Acta Polym. 1994, 45, 59-67.

(22) Xu, D.; Hodges, C.; Ding, Y.; Biggs, S.; Brooker, A.; York, D. A QCM Study on the Adsorption of Colloidal Laponite at the Solid/Liquid Interface. Langmuir 2010, 26, 8366-8372.

(23) Podsiadlo, P.; Shim, B. S.; Kotov, N. A. Polymer/clay and polymer/carbon nanotube hybrid organic-inorganic multilayered composites made by sequential layering of nanometer scale films. Coord. Chem. Rev. 2009, 253, 2835-2851.

(24) Ariga, K.; Lvov, Y.; Ichinose, I.; Kunitake, T. Ultrathin films of inorganic materials ( $\mathrm{SiO} 2$ nanoparticle, montmorillonite microplate, and molybdenum oxide) prepared by alternate layer-by-layer assembly with organic polyions. Appl.Clay Sci. 1999, 15, 137-152.

(25) Lin, Z.; Renneckar, S.; Hindman, D. P. Nanocomposite-based lignocellulosic fibers 1. Thermal stability of modified fibers with clay-polyelectrolyte multilayers. Cellulose 2008, 15, 333-346.

(26) Yan, N.; Masliyah, J. H. Adsorption and desorption of Clay Particles at the Oil-Water Interface. J. Colloid Interface Sci. 1994, 386-392.

(27) Coelho, A. C. V.; Santos, P.; Santos, H. Argilas especiais: argilas quimicamente modificadas-uma revisão. Química Nova 2007, 30, 1282.

(28) Ruzicka, B.; Zulian, L.; Ruocco, G. More on the Phase Diagram of Laponite. Langmuir 2006, 22, 1106-1111.

(29) Fripiat, J.; Cases, J.; Francois, M.; Letellier, M. Thermodynamic and microdynamic behavior of water in clay suspensions and gels. J. Colloid Interface Sci. 1982, 89 (2), 378-400.

(30) Balnois, E.; Durand-Vidal, S.; Levitz, P. Probing the Morphology of Laponite Clay Colloids by Atomic Force Microscopy. Langmuir 2003, 6633-6637.

(31) Tawari, S. L.; Koch, D. L.; Cohen, C. Electrical Double-Layer Effects on the Brownian Diffusivity and Aggregation Rate of Laponite Clay Particles. J. Colloid Interface Sci. 2001, 240, 54-66.

(32) Mongondry, P.; Nicolai, T.; Tassin, J.-F. Influence of pyrophosphate or polyethylene 
oxide on the aggregation and gelation of aqueous laponite dispersions. J. Colloid Interface Sci. 2004, 275 (1), 191-196.

(33) Teixeira, R. F.; McKenzie, H. S.; Boyd, A. A.; Bon, S. A. Pickering emulsion polymerization using Laponite clay as stabilizer to prepare armored "soft" polymer latexes. Macromol. 2011, 44 (18), 7415-7422.

(34) Sauerbrey, G. Z. Use of quartz vibration for weighing thin films on a microbalance. Physik J. 1959, 155, 206-212.

(35) Keiji Kanazawa, K.; Gordon II, J. G. The oscillation frequency of a quartz resonator in contact with liquid. Anal. Chim. Acta 1985, 175, 99-105.

(36) Fatisson, J.; Domingos, R. F.; Wilkinson, K. J.; Tufenkji, N. Deposition of TiO2 Nanoparticles onto Silica Measured Using a Quartz Crystal Microbalance with Dissipation Monitoring. Langmuir 2009, 25, 6062-6069.

(37) Chen, K. L.; Elimelech, M. Aggregation and Deposition Kinetics of Fullerene (C60) Nanoparticles. Langmuir 2006, 22, 10994-11001.

(38) Enarsson, L.-E.; Wagberg, L. Conformation of preadsorbed polyelectrolyte layers on silica studied by secondary adsorption of colloidal silica. J. Colloid Interface Sci. 2008, 325, 8492.

(39) Quevedo, I. R.; Tufenkji, N. Influence of Solution Chemistry on the Deposition and Detachment Kinetics of a CdTe Quantum Dot Examined Using a Quartz Crystal Microbalance. Environ. Sci. Technol. 2009, 43, 3176-3182.

(40) Jatav, S.; Joshi, Y. M. Chemical stability of Laponite in aqueous media. Appl. Clay Sci. 2014, 97-98, 72-77.

(41) Aveyard, R.; Binks, B. P.; Clint, J. H. Emulsions stabilised solely by colloidal particles. Adv. Colloid Interface Sci. 2003, 100-102, 503-546.

(42) Chevalier, Y.; Bolzinger, M.-A. Emulsions stabilized with solid nanoparticles: Pickering emulsions. Colloids Surfaces A: Physicochem. Eng. Aspects 2013, 439, $23-34$.

(43) Langmuir, I. The Constitution and Fundamental Properties of solids and liquids. Part I. Solids. J. Am. Chem. Soc. 1916, 38, 2221-2295.

(44) Brunauer, S.; Emmett, P. H.; Teller, E. Adsorption of Gases in Multimolecular Layers. J. Am. Chem. Soc. 1938, 60, 309-319.

(45) Ebadi, A.; Mohammadzadeh, J. S. S.; Khudiev, A. What is the correct form of BET isotherm for modeling liquid phase adsorption? Adsorption 2009, 15, 65-73.

(46) Prestidge, C. A.; Barnes, T.; Simovic, S. Polymer and particle adsorption at the PDMS droplet-water interface. Adv. Colloid Interface Sci. 2004, 108, 105-118. 
TOC Graphic

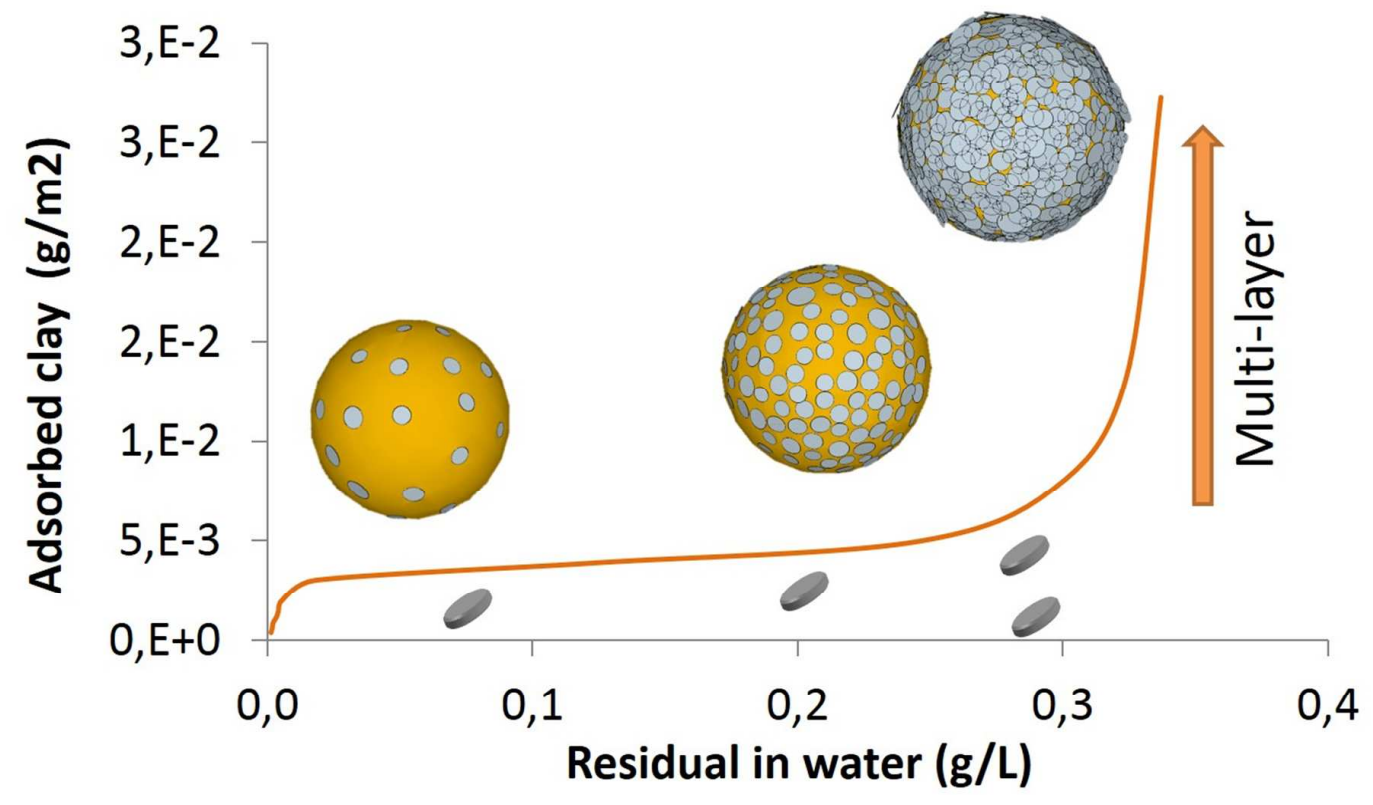

